\title{
La variación genérico-discursiva de la atenuación como resultado de la variación de la imagen
}

\author{
Marta Albelda Marco \\ Universitat de València
}

El presente trabajo investiga en qué medida la atención a la imagen social incide en la expresión de la atenuación. Para ello se realiza un estudio de los mecanismos atenuantes en cinco géneros discursivos seleccionados por su diferente tratamiento de la imagen: artículos de investigación, foros de comunicación en línea, conversaciones coloquiales, mesas redondas de discusión de expertos y debates políticos. Los resultados muestran variación tanto en las formas empleadas como en las funciones atenuantes, de acuerdo con las diferentes necesidades de imagen que origina cada género. Ello constituye un fuerte argumento a favor de la implicación de la noción de imagen en la caracterización de la atenuación.

Palabras clave: atenuación, imagen, variación lingüística, géneros discursivos

\section{Introducción ${ }^{1}$}

La atenuación se ha desarrollado extensamente en los últimos treinta años en el campo de la Pragmática a partir de trabajos como el de Fraser (1980) o el de Briz (1995) - este último para la lingüística española. También ha recibido un fuerte tratamiento en los estudios del discurso científico y académico, puesto que los hedges forman parte de las convenciones de la escritura académica (Markkanen y Schröder 1997; Hyland 1998; Oliver del Olmo 2005; Morales 2010; entre otros). Sin embargo, todavía este fenómeno sigue presentando problemas en su reconocimiento, pues se aprecian divergencias entre los autores a la hora de analizar

1. Este trabajo ha sido desarrollado gracias a la financiación recibida en el proyecto "La atenuación pragmática en su variación genérica: géneros discursivos escritos y orales en el español de España y América" (MINECO, FFI2016-75249-P). 
formas y expresiones atenuantes. Hace falta, por tanto, seguir trabajando en sus criterios de reconocimiento y buscar un consenso en los rasgos que la definen.

Con el objetivo de examinar el papel de la imagen en la caracterización de la atenuación, este artículo se propone estudiar cómo varían los mecanismos atenuantes en diferentes géneros discursivos a partir de la variación de imagen en cada género. Entre las características que diferencian a los géneros discursivos se encuentra un específico tratamiento de la imagen de los interlocutores involucrados en cada uno de ellos (Figueras, este volumen). Si se constata una variación por géneros de los mecanismos y funciones atenuantes en relación con la variación en las necesidades de imagen, dispondremos de una prueba más a favor del papel de la imagen como motor de la atenuación. Esta investigación pretende contribuir a establecer una definición de atenuación que dé cuenta de todos los usos que bajo ella se engloban.

El tratamiento de la imagen en cada género discursivo viene determinado por sus objetivos (propósitos) comunicativos y por la naturaleza de participantes que intervienen. Atender y ajustarse a las expectativas de imagen de cada género es un requisito más del éxito comunicativo. Se parte, pues de la hipótesis de que la atenuación es uno de los principales modos de responder a las necesidades de imagen generadas por los fines retóricos del género, y en cada caso sirven a funciones vinculadas a las características del género.

Se ha llevado a cabo un análisis exploratorio sobre un corpus de cinco géneros: artículos de investigación, foros de comunicación en línea, conversaciones coloquiales, mesas redondas de discusión de expertos y debates políticos. Estos géneros presentan rasgos en contraste en el canal de comunicación, en el carácter dialogal/monologal, en la repercusión social que presentan, en los rasgos situacionales y en la función comunicativa primordial del género.

La estructura del trabajo es la siguiente. En el Apartado 2 se revisa la definición de atenuación y los criterios que se han señalado para reconocerla; se exponen y valoran los criterios que inciden en cómo se expresa la atenuación (ver 2.1) y los que se refieren a la función que la atenuación desempeña en la comunicación (en 2.2). En el Apartado 3 se presenta el estudio exploratorio de la atenuación en el corpus de los cinco géneros discursivos estudiados; se explican sus principales rasgos (ver 3.1), se exponen los resultados de los mecanismos atenuantes empleados en cada género y se justifican en relación con las necesidades de imagen de cada género (3.2); en la Sección 3.3 se comparan los resultados de la atenuación en cada género y se presentan las conclusiones sobre la incidencia de la imagen en este fenómeno.

La investigación ofrecida en este artículo se complementa con el trabajo de Figueras (en este mismo volumen) sobre la variación de la imagen a través de 
diferentes géneros discursivos; ambos trabajos se han realizado sobre el mismo banco de datos.

\section{Criterios para definir y reconocer la atenuación}

2.1 Cómo: El significado difuso y la reducción de la fuerza ilocutiva

El fenómeno de la atenuación se desarrolla a partir del estudio de los hedges en la semántica modal. Lakoff (1972) observó que hay usos lingüísticos a los que no pueden atribuirse valores de verdad. Ante un ejemplo como el siguiente - del propio autor -,

(1) George Wallace and Adolf Hitler are sort of similar,

no se podría juzgar como verdadero o como falso que el hablante encuentre un parecido entre George Wallace y Adolf Hitler, pues el hedge "sort of" expresa un valor intermedio entre "ser similar" y "no ser similar" (Lakoff 1972:485). Así, el efecto provocado - y buscado - por el hedge es transmitir un significado difuso.

A partir del trabajo de Lakoff (1972) y con la incorporación a la lingüística de la noción pragmática de fuerza ilocutiva y su carácter gradual, se apunta que también la disminución intencionada de la fuerza ilocutiva en un enunciado puede emplearse con fines atenuantes. Así, en un ejemplo como

(2) Por favor, ¿me podría servir un marroncito?

(Briz 2006:9)

"la fórmula por favor, junto al valor de posibilidad del verbo poder y su empleo temporal condicional, minimizan directamente la [fuerza ilocutiva de] afirmación" (Briz 2006:9). Numerosas caracterizaciones de la atenuación incluyen la reducción de la fuerza ilocutiva como uno de sus rasgos fundamentales (Fraser 1980; Holmes 1984; Bazzanella et al. 1991; Briz 2006, 2012; Sbisà 2001; Caffi 2007; Czerwionka 2010; Thaler 2012; Schneider 2013; Barros 2017; Cestero 2016, Fuentes 2016; Villalba 2016; Samper 2017, etc.).

El empleo de expresiones difusoras del significado y la reducción de la fuerza ilocutiva son dos vías fundamentales para expresar atenuación. Algunos autores reconocen que no siempre son dos caminos independientes, sino que las formas de lenguaje borroso sirven, a su vez, para reducir la fuerza ilocutiva del acto en el que se emplean (Holmes 1984; Meyer-Hermann 1988; Bazzanella et al. 1991; Briz 1995, 2012; Sbisà 2001; Caffi 2007; Albelda y Cestero 2011). Reducir la fuerza ilocutiva es, pues, un primer rasgo y criterio para reconocer que un enunciado está atenuado. Sin embargo, este criterio es resbaladizo, pues no siempre es fácil 
averiguar en qué sentido la intención del hablante se ve reducida. Veámoslo a la luz de algunos ejemplos del corpus aquí estudiado:

(3) Z: habéih llega(d)o un poquillo tarde ¿no?

I: loh percanceh del autobúh

(Conversación. Corpus Cogila. Barros et al. 2012. Conversación 1, líneas 20-21)

(4) P: claro/ de todas formas eh/ doctora/ muchas de estas personas se avergüenzan $\dot{¿}^{\text {no? }}$ de tener este tipo de trastorno/ ¿tardan en pedir ayuda? C: ( ...) en el trastorno por atracón es como que buscan la solución en la dieta (Mesa redonda de expertos)

(5) Creo que poco puedo decirte aparte de lo que ya sabes. Deberías ponerte en manos de un profesional y confiar en él, con mentiras no vas a llegar a ningún lado

(Foro en línea TCA)

(6) Todavía hoy, la "ampliación de la frontera agrícola" constituye una oferta electoral válida en países en los que el fuego y los buldózer son vistos por muchos como los mejores aliados de su desarrollo. Todos estamos familiarizados con la vertiginosa desaparición del bosque intertropical, donde se han perdido millones de hectáreas en la última década (Artículo científico. Tellería 2013:16)

(7) Estos autores clasifican los aproximadores en adaptadores (...) y redondeadores (...), los cuales modifican el contenido "by indicating that some term is a rounded-off representation of some figure" (Prince et al. 1982:93). Respecto a los adaptadores, conviene perfilar cómo se lleva a cabo la expresión del ajuste entre lo dicho y lo percibido o pensado. (Artículo científico. Llopis 2016:108)

En los Ejemplos (3) y (4) tenemos mecanismos de atenuación del contenido proposicional, dado que tienen ámbito sobre una parte del enunciado. Son difusores del significado: el cuantificador minimizador con el diminutivo en (3), "un poquillo", y la partícula difusora "como que" en (4). Como hemos señalado arriba, algunos autores consideran que los procedimientos de lenguaje borroso reducen también la fuerza ilocutiva en tanto que afectan a la intención expresada en el acto de habla; para Briz (1995) atenúan también la fuerza ilocutiva de forma secundaria (o indirecta). En el Ejemplo (3) los procedimientos atenuantes reducen la fuerza de la recriminación; en (4) reducen la fuerza de la aserción/opinión.

Los usos atenuantes de las muestras (4; intervención de P: ¿no?), (5), (6) y (7) tienen ámbito sobre todo el enunciado y no son difusores del significado. El marcador fático-apelativo “¿no?" (4) reduce la fuerza de la aserción/opinión, al igual que lo hace el verbo "creo" en (5); el uso del condicional "deberías" (5) minimiza la fuerza de la recomendación/consejo. Para Briz (1995) son primariamente atenuantes de la fuerza ilocutiva. 
En (6) y (7) tenemos otro tipo de mecanismos: son atenuantes del papel de los hablantes en la enunciación (Briz 1995) o shields (Caffi 2007). En ellos el enunciador se esconde detrás de expresiones impersonales. En (6) la atenuación se expresa mediante "todos estamos familiarizados con + P": el hablante da por sentada la proposición $\mathrm{P}$ y evita hacer una afirmación desde el yo empleando una forma inclusiva de conocimiento. "Conviene perfilar" (7) es otro mecanismo de desfocalización del yo-enunciador, que acude a una expresión deóntica con sujeto no personal.

En los Ejemplos (3), (4) y (5) puede apreciarse sin problema la reducción de la fuerza ilocutiva (atenuación primaria y secundaria de la fuerza, según Briz 1995). Quienes forman parte del contexto de habla reconocen la verdadera intención del hablante e implican que se ha expresado lingüísticamente en un grado menor al de la intención original. En ese sentido, son actos de habla indirectos, pues la atenuación supone un desajuste entre lo dicho y lo que se ha querido decir; en otras palabras, hay un fingimiento intencionado. Por ejemplo, el hablante de (3), en realidad, no considera que sus interlocutores solo han llegado "un poquillo tarde", sino que su apreciación es mayor. Gracias al valor manipulador y estratégico de la atenuación puede expresarlo de manera más suave y proteger, así, las imágenes de sus interlocutores.

En otros usos no resulta tan transparente la reducción de la fuerza ilocutiva, particularmente sucede cuando los atenuantes son shields (Ejemplos (6) y (7)). En "Todos estamos familiarizados con la vertiginosa desaparición del bosque intertropical", no se expresa una afirmación más suave sino que se crea el efecto de que lo dicho es compartido y accesible por cualquier lector. El tipo de procedimiento estratégico es, pues, diferente: consiste en desfocalizar la figura del hablante como responsable de lo dicho (Villalba 2016:215); frente a lo que, por ejemplo, sucedía en (5) "creo que poco puedo decirte aparte de lo que ya sabes", donde la hablante muestra su conocimiento tan solo como una creencia cuando en realidad tiene seguridad sobre lo que dice (Soler 2018).

Como se observa en estos ejemplos de shields, el criterio de la reducción de la fuerza ilocutiva se puede tornar problemático. Ante ello, caben dos posibles soluciones: considerar que en estos casos no hay tal reducción de la fuerza sino que se trata de otro procedimiento de atenuación; o adoptar una visión amplia de la gradación de la fuerza ilocutiva y considerar que el hecho de esconder la primera persona de la enunciación supone una reducción de la afirmación. En este sentido, también se podría reconocer indirección en tales actos de habla, pues se consideraría un desajuste entre la intención del hablante (no expresada: en (6) "yo conozco/afirmo la vertiginosa desaparición del bosque intertropical; en ( 7 ) "voy a perfilar/quiero perfilar...") y las palabras expresadas. 
En síntesis, hemos revisado tres posibles criterios para definir y reconocer los usos atenuantes: la expresión de lenguaje difuso, la reducción de la fuerza ilocutiva y, como consecuencia, la indireccionalidad de los actos de habla atenuados, puesto que se crea un desajuste, fruto de una simulación intencionada, entre la intención del hablante y la expresión lingüística realizada. Para los atenuantes que son shields, si no se acepta el criterio de la reducción de la fuerza ilocutiva, habría que añadir un criterio a la definición, el de la desfocalización del papel de los hablantes de la enunciación (Briz 1995; Caffi 2007). Sin embargo, siendo estos criterios orientativos, además de los problemas de aplicación que pueden representar, solo dan cuenta de cómo se expresa la atenuación y no de su función.

\subsection{Para qué: La función retórica y la función protectora de la imagen}

Los criterios anteriores, aun siendo necesarios, son insuficientes para dar cuenta completa del fenómeno de la atenuación: no informan sobre el para qué de su uso. Entre las figuras de persuasión retórica y argumentativa de los tratados de retórica griega y latina, encontramos ya recogida la atenuación, como se aprecia en el catálogo de la Retórica a Herenio ${ }^{2}$ (9o a.C., XXXVIII):

La deminutio se da cuando decimos que por naturaleza, fortuna o esfuerzo hay algo extraordinario en nosotros o en las personas que defendemos. Para que esto no se interprete como ostentación arrogante se modera y atenúa con alguna expresión, por ejemplo: Pues tengo el derecho de decir, jueces, que he procurado con trabajo y esfuerzo dominar el arte militar no contentándome con ser de los peores. Aquí si se hubiese dicho dominarlo a la perfección, aunque respondiese a la verdad, sin embargo habría parecido arrogante. Ya he dicho suficiente sobre cómo evitar la envidia y conseguir la alabanza.

Esta explicación de la deminutio da cuenta de su finalidad, obtener la aprobación y la afección de los interlocutores para lograr una mayor eficiencia comunicativa. Se aprecia que la atenuación desempeña una función retórica en la comunicación, que se centra en la relación entre el mensaje y los interlocutores, y tiene en cuenta los riesgos que estos adquieren en la interacción.

Este rasgo se plasma de diferente manera en diversas definiciones de la atenuación. Muchas señalan que reduce el compromiso del hablante con lo dicho (Prince et alii 1982, Briz 2006, 2012; Cestero 2015; Fuentes 2016; Albelda 2018) o las obligaciones de los participantes con el mensaje (esto es, las limitaciones a la libertad de acción que su discurso genera; Meyer-Hermann 1988; Bazzanella et al. 1991; Caffi 2007; Schneider 2017). Otras definiciones hablan también de la imagen

2. De autor desconocido; atribuida original pero erróneamente a Cicerón. 
como motor de la atenuación: "mitigation is a modification of only those effects which are unwelcome to the hearer" (Fraser 1980:342). En cierto sentido, y dependiendo de la amplitud con que se aborde la noción de imagen, podrían verse los compromisos y obligaciones de los hablantes como componentes de su imagen. ${ }^{3}$ Aunque cada vez parece ser más común incluir la protección de la imagen en las caracterizaciones del fenómeno (Briz 2006; Czerwionka 2010; Thaler 2012; Schneider 2013; Albelda 2016; Cabedo 2016; Villalba 2016; Hernández-Flores y Rodríguez en este volumen, entre otras), no siempre se menciona. En algunos casos la definición se queda en términos del compromiso o las obligaciones del hablante.

La reticencia a incluir la noción de imagen en la caracterización de la atenuación (Briz y Albelda 2013; Albelda et al. 2014; Cestero 2015) quizás se deba al deseo de definirla con medios exclusivamente lingüísticos y a considerar secundario que afecte a la esfera social. Sin embargo, de acuerdo con los estudios empíricos cada vez más frecuentes sobre este fenómeno, ${ }^{4}$ parece necesario contar con el criterio de la imagen para reconocer que un enunciado está atenuado frente a otro que no lo está (Albelda 2016). De esta forma, además de explicar cómo se lleva a cabo el proceso de atenuación (en la Sección 2.1), se podría dar cuenta de la finalidad última de la atenuación.

La noción de imagen ha sido incorporada a los estudios del discurso y discutida en diversos trabajos. Siguiendo a Hernández-Flores (2013:190), se consideran tres tipos de actividades de imagen: (i) autoimagen, cuando se produce un efecto social positivo en el hablante y un efecto neutro en el oyente; (ii) cortesía (atención a la heteroimagen), la cual supone efectos sociales positivos en ambos interlocutores; y (iii) descortesía (ataque a la heteroimagen), con efectos negativos en ambos interlocutores (en el caso del hablante, podrán ser efectos positivos, como ocurrirá aquí). Teniendo en cuenta la propuesta de Figueras (en este volumen), además del efecto social de la imagen, se considera que esta también incide en otras dimensiones, como la afectiva y cognitiva. En la interacción los hablantes velan por la imagen de sus interlocutores reconociéndoles los atributos que desean (dimensión social y afectiva), y también construyen su propia representación de imagen e identidad (dimensión cognitiva). Asimismo, y en relación con los diversos géneros discursivos, es conveniente reconocer la imagen de rol o imagen profesional (Bravo 2002; Hernández-Flores 2013; Albelda 2016; Figueras este

3. Véase, en este sentido, la discusión de Figueras, en este volumen.

4. Entre otros, se pueden mencionar los estudios de Cestero y Albelda (2011), Contreras (2012), Estellés (2013), Flores-Treviño (2016), Cestero (2015, 2017), Cabedo (2016), González y García (2016), Samper (2017), Soler (2018), Douglas, Vuoto y Soler (2018), etc. 
volumen), esto es, la imagen vinculada al papel que desempeña una persona en calidad de experto o de profesional en una situación determinada.

En el siguiente apartado se analizan los mecanismos atenuantes empleados en géneros discursivos con diferentes fines retóricos y diversas necesidades de imagen, con el objetivo de observar si varían genéricamente y si construyen diferentes reclamos de imagen de acuerdo con el género. La posible correlación entre variación de atenuantes y variación de imagen constituirá un argumento más a favor de la necesidad de incluir la imagen en la definición de atenuación.

\section{Estudio de la variación de la atenuación en cinco géneros discursivos}

\subsection{Caracterización de los géneros discursivos del corpus}

Los géneros discursivos son moldes comunicativos diseñados sobre diversos rasgos, entre ellos, unos concretos fines comunicativos y unas determinadas necesidades de imagen. Se han tomado cinco géneros para hacer una primera exploración sobre la variación en los mecanismos atenuantes. Se han seleccionado en función de sus diferencias. Los géneros trabajados escritos y orales, monológicos y dialógicos, cara a cara y a través de canales de intermediación (papel, internet, televisión), con fines transaccionales y con fines interpersonales, con impacto (o ausencia de este) en la esfera pública, con interlocutores conocidos y desconocidos, y con diferentes fines retóricos y diversas necesidades de imagen, de acuerdo con las exigencias de cada género.

El corpus está conformado por 40 ooo palabras. En primer lugar, se han analizado 10 ooo palabras correspondientes a artículos científicos de cuatro disciplinas, escritos en español por autores de España: Arquitectura y Edificación, Educación, Biología y Lingüística. ${ }^{5}$ Son géneros escritos monológicos de consumo profesional, y por tanto, con una clara finalidad transaccional. Transmiten la investigación realizada por un científico o un equipo y se destinan a expertos del mismo campo, que son, en principio, desconocidos por el autor. El texto tiene incidencia pública; los lectores van a valorar a la persona del científico a través de su trabajo

5. Tellería, J. L (2013): "Pérdida de biodiversidad. Causas y consecuencias de la desaparición de las especies”. Memorias R. Soc. Esp. Hist. Nat., 10, 13-25; Cecchini-Estrada, J. A. et al. (2015): "Perfiles contextuales y su relación con las variables disposicionales en el aprendizaje del alumnado de Educación Secundaria". Estudios sobre educación 28, 29-50; Lozano, C. et al. (2013): "Disminución de la probabilidad de atascos por la presencia de un obstáculo cerca de la salida". Revista de Edificación, 41-42, 102-107; Llopis, A. (2016): "De la indeterminación a la atenuación: de alguna manera/ forma/ modo", Revista Internacional de Lingüística, 105-121. 
científico. La finalidad comunicativa del género es persuadir a los lectores de la validez de la investigación y de su valía como investigadores.

En segundo lugar, se ha examinado un corpus de 10 ooo palabras de foros de mensajes en línea sobre personas con trastornos en la conducta alimenticia (TCA). ${ }^{6}$ Son textos escritos en foros de internet donde participan personas con estas enfermedades y otros usuarios que las sufrieron en otro momento, o que simplemente participan en el foro para dar consejos. La comunicación es interpersonal, el fin comunicativo es compartir sentimientos personales, dudas y miedos que los enfermos sufren para intentar afrontar la enfermedad; de ahí que se creen espacios para recibir apoyo y consejos. Los interlocutores no se conocen personalmente, pero tienden a realizar confesiones muy personales. Estos foros no tienen una incidencia pública, son espacios en que no se desvelan las identidades y se comunica de manera privada.

En tercer lugar, se ha analizado una mesa redonda de discusión de expertos sobre enfermedades TCA (5 ooo palabras). ${ }^{7}$ Es un diálogo cara a cara televisado, por tanto, con impacto público. El tono es formal y los hablantes actúan en su rol de profesionales para, con base en sus conocimientos, informar de cuestiones técnicas sobre el tema en cuestión; un moderador guía la mesa redonda y realiza preguntas y comentarios a los tertulianos. La finalidad es informativa y, parcialmente, persuasiva puesto que aportan su visión y experiencia.

En cuarto lugar, se ha analizado un debate electoral cara a cara entre dos líderes políticos candidatos a la presidencia del gobierno (Rodríguez Zapatero y Rajoy), bajo la guía de un moderador (5 ooo palabras). ${ }^{8}$ El debate es cara a cara, televisado, con gran impacto público y con una fuerte finalidad argumentativo-persuasiva, pues de las aportaciones de los candidatos dependen en parte los resultados electorales. Asimismo, en buena parte, la persuasión consiste en destruir la imagen y las aportaciones del oponente.

Por último, se han analizado dos conversaciones coloquiales (corpus Val.Es.Co., Briz et al. 2002, de Valencia y corpus COGILA, Barros et al. 2012, de Granada) que suman 10 ooo palabras. Intervienen jóvenes estudiantes, amigos, en espacios familiares y en un tono distendido y relajado. El género es oral, dialogal

6. Se ha obtenido en la página http://salud.enfemenino.com/foro; corresponden a los últimos diez años.

7. Emitido el 18/02/2013, TVE2. "Para Todos La 2. Trastornos alimentarios". Además del presentador (P), participaron tres expertos: Rosa Calvo (RC), Vicente Turón (VT) e Idoia Dúo (ID).

8. 25/02/2008, IFEMA, Academia de las Ciencias y las Artes de Televisión; moderado por Manuel Campo. 
y cara a cara y su incidencia es privada. La finalidad comunicativa es socializar y reforzar los lazos de amistad entre los interlocutores.

\subsection{Análisis de los mecanismos atenuantes en cada género discursivo}

Para el reconocimiento de los mecanismos atenuantes, se han tenido en cuenta los criterios señalados en las Secciones 2.1 y Secciones 2.2: expresión de significados difusos, reducción de la fuerza ilocutiva (e indireccionalidad entre la intención original del hablante y su plasmación lingüística), desfocalización del papel de los hablantes de la enunciación. Aunque el reconocimiento es contextual, hay formas y mecanismos que tienden preferentemente a expresar atenuación (Holmes 1984; Bazzanella et al. 1991; Meyer-Hermann 1988; Briz 1995; Caffi 2007; Cestero y Albelda 2011; Albelda et al. 2014). En este caso, se ha tomado como punto de partida el catálogo de mecanismos de atenuación expuesto en Albelda et al. (2014), que incorpora los mecanismos señalados por la bibliografía anterior.

Una vez identificados los atenuantes, se han agrupado siguiendo la taxonomía de movimientos comunicativos y cognitivos generales que pueden llevar a cabo (Albelda y Cestero 2011). Esta categorización facilitará la comparación entre los géneros y permitirá asociar los usos atenuantes con las necesidades de imagen que los motivan:

A. Minimizar o difuminar la cantidad o cualidad de lo dicho (cuantificadores, modificadores del contenido semántico, litotes, eufemismos, etc.).

B. Rebajar la aserción expresándola en forma de duda o incertidumbre.

C. Desfocalizar los elementos de la enunciación personal (impersonalizadores, evidenciales, etc.).

D. Acotar o restringir lo dicho a un determinado punto de vista personal o ámbito temporal.

E. Justificar (conectores y estructuras causales, explicativas, consecutivas lógicas, excusas, etc.).

F. Corregir o reparar tras un desacuerdo o disconformidad (expresiones correctoras, disculpas).

G. Realizar concesiones (que suponen acuerdos parciales con el interlocutor).

H. Implicar al tú en lo dicho por el hablante (fático-apelativos, enunciados suspendidos, etc.).

I. Formular actos directivos de forma indirecta (consejos, peticiones, órdenes, etc.),

A continuación, se presentan los tipos de movimientos comunicativos y cognitivos más frecuentes de los atenuantes observados en cada género y se relacionan con el papel que realizan los interlocutores en cuanto a su imagen en cada género, 
y su finalidad comunicativa. Los tipos de actividades de imagen analizados son los presentados en la Sección 2.2: autoimagen, heteroimagen cortés, heteroimagen descortés e imagen de rol.

\section{a. Artículos científicos}

Los artículos científicos se especializan en determinados mecanismos atenuantes. Aunque se han tenido en cuenta sus diversas partes estructurales (introducción, estado de la cuestión, metodología, resultados y discusión), en todas ellas, son recursos muy coincidentes. Se emplean, sobre todo, desfocalizadores de la enunciación personal (C): estructuras impersonales - pronombres y formas verbales -, nominalizaciones y evidenciales $(8,9,10)$. También se emplean atenuantes que rebajan la aserción expresándola en forma de duda o incertidumbre (B) (parecer, poder, ser posible, condicionales...) (11), se realizan justificaciones (E) de las decisiones tomadas en la investigación o de las afirmaciones realizadas (12), y se acotan las aserciones al punto de vista del hablante (D) (11).

(8) Estas ideas han llevado a clasificar a las especies según su papel en un determinado sistema ecológico.

(Tellería 2013:21)

(9) Los resultados muestran, también, que no se observa ninguna polarización de la acción docente.

(Cecchini-Estrada et al. 2015:43)

(10) Es lógico plantearse que si la presencia del obstáculo favorece que el sistema se atasque menos, esto puede ser debido a que (...)

(Lozano et al. 2013:104)

(11) En nuestra opinión, se podrían distinguir las siguientes categorías.

(Llopis 2016:107)

(12) Sin embargo, debido a que este análisis es exploratorio, es importante confirmar los resultados con una muestra independiente.

(Cecchini-Estrada et al. 2015:35)

Pueden verse dos finalidades comunes en los mecanismos atenuantes empleados en los artículos científicos estudiados. Por un lado, el autor científico trata de desaparecer del texto y, por tanto, de la investigación, con el fin de hacerla más objetiva y accesible a sus colegas. Presenta sus afirmaciones como hechos compartidos por la ciencia y traslada la responsabilidad del ejercicio investigador al propio estudio, que se personifica y se convierte en el sujeto de la acción investigadora. Por otro lado, el autor procura reducir la asertividad de sus ideas $\mathrm{y}$ afirmaciones, lo que le permite mostrar una imagen personal de humildad y apertura, que además le protege de los posibles errores, críticas o rechazo que podría suscitar su investigación. 
En definitiva, la atenuación en los artículos de investigación está al servicio de la aprobación por parte de la comunidad científica del contenido científico expuesto. Metonímicamente, aprobar el contenido del trabajo supone aprobar la imagen de experto de su autor. Se manifiesta, pues, un deseo de autoimagen de experto.

\section{b. Foros de mensajes en línea}

Los mecanismos atenuantes en los foros TCA se localizan, en general, en las intervenciones reactivas de consejo (y de testimonio) ${ }^{9}$ a las personas que han confesado síntomas y sentimientos hacia enfermedades alimentarias. En estas situaciones las imágenes de los enfermos resultan muy vulnerables, por lo que los atenuantes se concentran en reducir la amenaza que pueden suponer los actos directivos de consejo y la descripción de lo que podrían padecer las personas con estos síntomas si no se tratan médicamente.

Junto con comentarios muy directos y poco atenuados, hay otros atenuados. Las estrategias de impersonalización y generalización, desfocalizadoras de las personas de la enunciación (C), permiten no evaluar directamente la conducta de la persona enferma:

(13) dices ya iré, ya hablaré con la familia, y a la de nada te plantas 10 años con trastorno y terapias que ya casi no sirven de nada porque ya no sabes ni quien eres sin esto.

(14) De ahí que sin darnos cuenta, estemos pavas o seamos súper-coherentes, seamos unas inmaduras o carguemos la responsabilidad de medio mundo en nuestros hombros.

La fuerza ilocutiva del consejo se reduce (I) a través de verbos modales, tiempos condicionales, verbos de creencia e incertidumbre, concesivas, minimizadores (A) $(15,16,17)$. Además, se implica al tú en lo dicho por el hablante $(\mathrm{H})$, depositando la responsabilidad en las palabras que ya dijo la propia persona enferma (16). Por último, se acude a reparaciones y justificaciones (disculpas) (F, E) cuando se calcula que la imagen de algún participante se ha visto o se podrá ver herida $(16,17)$ :

(15) No te digo que haya sido tu caso, ni mucho menos, con profesionales ineptos hemos topado casi todas, pero sí que te digo que pasa porque busques ayuda completa y no parches.

9. En las respuestas a la persona que expresa la enfermedad, además de ofrecer consejos, se exponen situaciones personales, si las personas han pasado por la misma situación. 
(16) Se ve, por lo que has ido explicando en tus post que te sientes sola, y que quieres desesperadamente que tu entorno esté pendiente de ti. Entiendo que tu sentimiento es que necesitas que te comprendan y que te ayuden, pero sin embargo lo que buscas, incoscientemente, es que estén pendientes de ti y alimenten tu autocompasión.

(17) Pues lo siento muchísimo, sorry si incomodo a alguien, pero no me di cuenta que me doy si soy algo egocéntrica, yo hablo que a mi me pasa también las cosas lo que siento es real y me uno a hablar.

Estos usos atenuantes no manifiestan ya un deseo de autoimagen, como en los artículos científicos, sino que se dirigen a proteger la imagen del receptor, en dos sentidos. Por un lado, en cuanto a su vulnerabilidad: se presupone en el receptor una necesidad de aprobación y respeto de su enfermedad y de su capacidad para afrontarla. Por otro lado, protegen la imagen del receptor para asegurarse la eficacia del objetivo comunicativo del consejo, que sea aceptado.

\section{c. Mesa redonda de expertos}

Los atenuantes empleados en la mesa redonda coinciden en gran parte con los atenuantes de los artículos científicos, pues en ambos se busca el reconocimiento de una imagen de experto, la cual implica en el caso español mostrarse humilde y no presentar impositivamente las ideas. En ese sentido, los movimientos atenuantes de este género son, sobre todo, la reducción de la aserción a través de expresiones de incertidumbre o duda (B), la restricción de lo dicho al punto de vista del hablante (D) (18) y justificaciones (E) (19):

(18) VT: yo creo que la OMS ahí se equivoca// la obesidad es el resultado de muchas causas// no una enfermedad concreta

(19) ID: hay cierta similitud entre el consumo de drogas/ o sea/ el cerebro responde de la misma forma cuando se consume la droga que cuando se consume estos alimentos // lo que pasa que a pesar de haber similitudes pues bueno pues hay detractores de todo esto ¿no?/ porque dicen que no podemos basarnos solamente en el efecto del placer o la recompensa por el consumo

También, al igual que en los artículos científicos, para lograr una mayor eficacia persuasiva en la comunicación de la ciencia, el experto tiende a objetivar su discurso y a esconderse detrás de impersonalizaciones, nominalizaciones y mecanismos de desfocalización de la enunciación personal (C): 
(20) P: hoy queremos hacer especial hincapié en aquellos trastornos del comportamiento alimentario que se caracterizan por comer de manera compulsiva la bulimia nerviosa o el trastorno por atracón (...) hay que decir que estas patologías no se curan solas/ parece casi obligatorio acudir a especialistas en la materia

Junto con la expresión de una imagen de experto, este género al ser dialógico y oral, con mayor impacto público, puesto que el canal es la televisión, y constituido por diversos roles funcionales, implica también acciones de protección de la imagen ajena. Apenas se produce desacuerdo, a diferencia del debate político, pero sí hay en algunas ocasiones, cuando se ofrecen puntos de vista diversos. Para esos casos, se recurre a mecanismos atenuantes de reparación $(F)$ y concesión $(G)$, difusores de lo dicho (A, en 21 es una litote) o implicadores del tú (H, en 21 son marcadores fáticos):

(21) A: un resultado que afecta sobre todo más a ellas que a ellos ¿no?/ por lo que parece ¿no?

VT: pues no es tan cierto

Por último, el moderador recurre a atenuantes del directivo de pregunta (en 22: perífrasis de gerundio, indirección de la pregunta, tiempo condicional):

(22) P: ya para concluir/ fundamentalmente tenemos que ir cerrando la tertulia/ me gustaría/ que nos dieran consejos de prevención ¿los hay?

En suma, los mecanismos atenuantes de este género se dirigen a la aprobación de dos tipos de imagen: la autoimagen de experto (también por metonimia, la aprobación del contenido científico) demandada por él/ella mismo/a, y el reconocimiento de una necesidad de preservación de la imagen pública por parte de los otros participantes.

\section{d. Debate político electoral}

En el debate político, cabe distinguir los roles del moderador y de los líderes políticos. En este caso, solo nos referiremos a las necesidades de imagen y a los usos atenuantes de los políticos, puesto que el comportamiento del moderador coincide con el de las mesas redondas de expertos.

En los debates políticos no es muy abundante la atenuación; por el contrario, se emplean muchos intensificadores. Es un género parcialmente caracterizado por el ataque a la imagen del político rival y por la expresión de una autoimagen pública de profesional competente, seguro y válido para desempeñar la tarea que aspira a ejercer.

Los casos de atenuación registrados provienen, sobre todo, del candidato cuya evaluación de su comportamiento y actividad se encuentra más amenazada, pues 
es el que ostenta el cargo de presidente del gobierno hasta el momento. Este justifica la situación política en la que se encuentra el país - fruto de su gobierno y generaliza la responsabilidad de dicha situación a una comunidad social, más allá de él mismo o de su partido político (C, desfocalizadores de la enunciación: impersonalización - sujetos en primera persona, inclusivos -, evidenciales) (23). Emplea también mecanismos difusores del significado (eufemismos, litotes) (A) y justificaciones (E) (24). Son usos atenuantes con un valor fuertemente retórico, dirigido a persuadir a la audiencia del buen gobierno que han llevado a cabo y a reparar su imagen ante algunas cuestiones sensibles que se han valorado sobre la situación del país:

(23) R: En los últimos años ha surgido un fenómeno nuevo y creciente, que es la inmigración, que puede afectar a estos pilares a los que acabo de hacer referencia. Son personas que vienen a España, que trabajan y que, en su mayoría, contribuyen. Pero también son los más necesitados (...) Por lo tanto para que lo que puede ser una operación de éxito no se convierta en un drama hay que poner un orden y control en el fenómeno migratorio.

(24) R: Ese balance nos da tranquilidad para asumir un proceso de desaceleración que tenemos en estos momentos, que es un proceso de desaceleración mundial.

Estos atenuantes revelan una necesidad de aprobar una autoimagen de valía y competencia profesional, reivindicada por el propio hablante y no reconocida ni aprobada por el interlocutor inmediato (el otro rival), sino más bien atacada. La construcción de dicha autoimagen individual implica en este género la construcción de una imagen colectiva, la del partido al que representa.

\section{e. Conversaciones coloquiales}

A diferencia de los géneros anteriores, en la conversación coloquial no hay restricción ni preferencia hacia algún recurso atenuante. En el subcorpus analizado se registran casos de todas las categorías establecidas. Detrás de estos usos se aprecian dos tendencias de imagen.

En primer lugar, algunos mecanismos atenuantes se especializan en la construcción de una imagen de grupo, en la que se busca integrar al interlocutor, respetarle y aprobar sus aportaciones y atributos personales. Para ello, se privilegia la negociación mediante diversos mecanismos: concesiones ( $G$, que suponen acuerdos parciales con los interlocutores) - estructuras concesivas, risas -; atenuantes que rebajan la aserción expresándola en forma de duda (B); restricción de las opiniones propias (D); justificaciones (E) (25); desfocalización de la enunciación personal (C) (26); implicación del tú en lo dicho $(\mathrm{H})$ (26); minimización de lo dicho (A) (27): 
(25) Z: yo creo que no ¿eh?/ eso no eh así/ ehcribih sí peroo a la(ho)ra d'hablah// eso eh que depende porque si tú (e)htá en tu pueblo ahí con tu familia pueeh $\rightarrow$ ¿porque tieneh que hablah como le hablaríaah a lo mejoh a un profesoh por ejemplo?/ (...) pueh yo no veo qu'eso sea así // pero bueno (RISAS) eso cada uno tiene su opinión

$\mathrm{N}$ : hombre yo creo que sí/ que sería lo suyo eeh hablah en condisioneh porque sino d'aquí a tresientoh añoh no noh vamoh a entendeh// pero güeno (RISAS) (Barros et al. 2012. Conversación 1. Líneas 285-291)

(26) Z: eso de la tendiditih dicen que eh bahtante complica(d)o que se quite ¿no?/ que una veh que te da ya noo $\rightarrow$

I: Julia tiene tendiditih de tocaaah la flauta// y tuvo que dejarlo

(Barros et al. 2012. Conversación 1. Líneas 109-111)

(27) D: y los guisantes congelados son una mierda también/ están to(d)oos

A: congelaos no están tan malos/ estáan bien// los que son una mierda son los de bote (Briz et al. 2002. Conversación H38.A1. Líneas 428-438)

En segundo lugar, se atenúan los actos de habla que puedan resultar más costosos al receptor, bien porque afectan a ámbitos personales, bien porque pueden atentar contra atributos personales socialmente reconocidos. Así, se reduce habitualmente la fuerza ilocutiva en toda la gama de directivos (peticiones, recomendaciones, recriminaciones, etc.) (I) (28), se recurre a justificaciones (E) y reparaciones (F), y se minimiza el contenido proposicional del directivo (A, en el caso de 29 el cuantificador y el diminutivo reducen la fuerza de la recriminación). Algunas de las mencionadas estrategias se emplean también para proteger los atributos sociales del interlocutor.

(28) D: esta tarde se podría ver una película de vídeo (petición atenuada)

B: y mañana otra (RISAS)

(Briz et al. 2002. Conversación H38.A1. Líneas 354-356)

(29) Z: habéih llega(d)o un poquillo tarde ¿no?

I: (RISAS) loh percanceh del autobúh

(Barros et al. 2012. Conversación 1. Líneas 20-21)

En definitiva, el análisis de la atenuación en la conversación manifiesta una necesidad de integración en el grupo (afiliación, Bravo 1999) y una necesidad de reconocimiento del territorio y atributos personales del hablante (autonomía, Bravo 1999). Como se aprecia, son dos tendencias en las que destaca la protección de la figura del oyente, lo cual tiene todo el sentido al ser la conversación el género socializador por excelencia. No obstante, como ya ha destacado la bibliografía (Hernández-Flores 2013; Figueras, este volumen, entre otros), especialmente en 
géneros tan socializadores, cuando se protege la imagen ajena, también se protege la imagen propia.

3.3 Qué revelan los mecanismos atenuantes de la imagen en cada género discursivo

La Tabla 1 resume los resultados de análisis mostrado en el apartado anterior y los presenta comparativamente:

En relación con las categorías atenuantes, la tabla recoge cuáles están presentes y cuáles ausentes en los géneros estudiados. La única excepción es la conversación, en la que se pueden emplear todas ellas, puesto que tampoco hay restricciones de imagen en este género, por ser considerado un macrogénero.

Respecto al resto de géneros, se advierten tendencias en la relación entre atenuantes y tipos de imagen:

- El artículo científico es el único género monológico estudiado y el único en el que los datos reflejan que se trabaja solo la autoimagen; no hay atención a la heteroimagen (de los lectores). Este hecho viene apoyado por las categorías atenuantes no registradas (F, G, H e I, excepto A); es decir, no se emplean protectores o reparadores de carácter interaccional. Por contra, los tipos de atenuantes utilizados tienen que ver con la protección de la autoimagen (del autor) (B, C, D y E): son mitigadores de sus aserciones y opiniones; están al servicio de proyectar una imagen de profesional experto basada en una argumentación objetiva (C), humilde (B, D) y sólida (E) de sus propuestas y resultados de investigación. Ello explica, también, la ausencia de atenuantes de la categoría (A).

- Los debates políticos coinciden con los artículos en no emplear algunas categorías atenuantes (F, G, H e I). A diferencia de los artículos, los debates sí son dialógicos; sin embargo, la ausencia de las categorías mencionadas se debe al carácter confrontacional del género, en el que sí hay conciencia de una heteroimagen, aunque no precisamente para protegerla sino para atacarla. Se entiende así que esos mecanismos de cuidado del tú en la negociación se omitan abiertamente. En el caso de los directivos indirectos (I), no se han registrado (tampoco en artículos) porque el propio género no incluye este tipo de actos entre sus acciones comunicativas. 


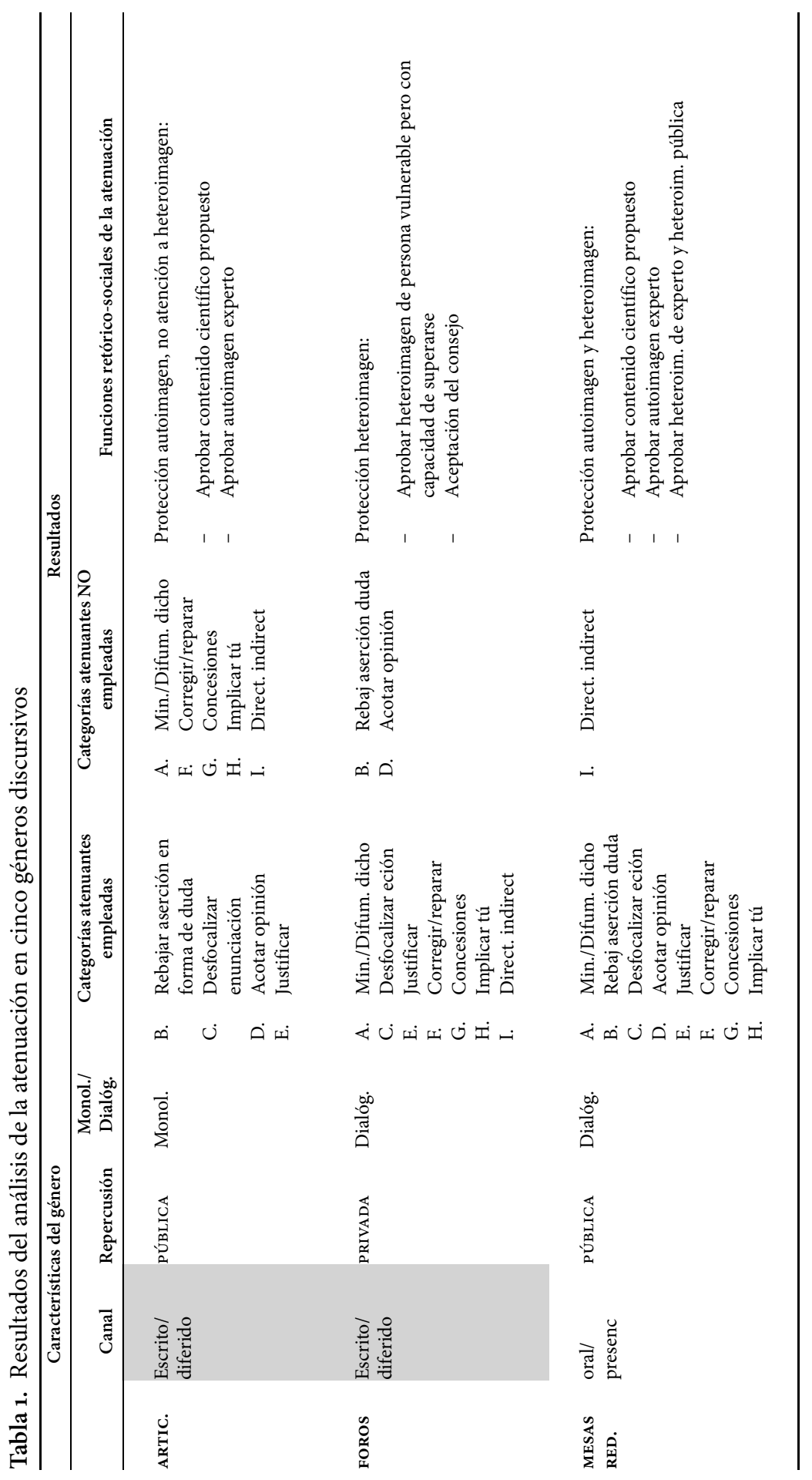




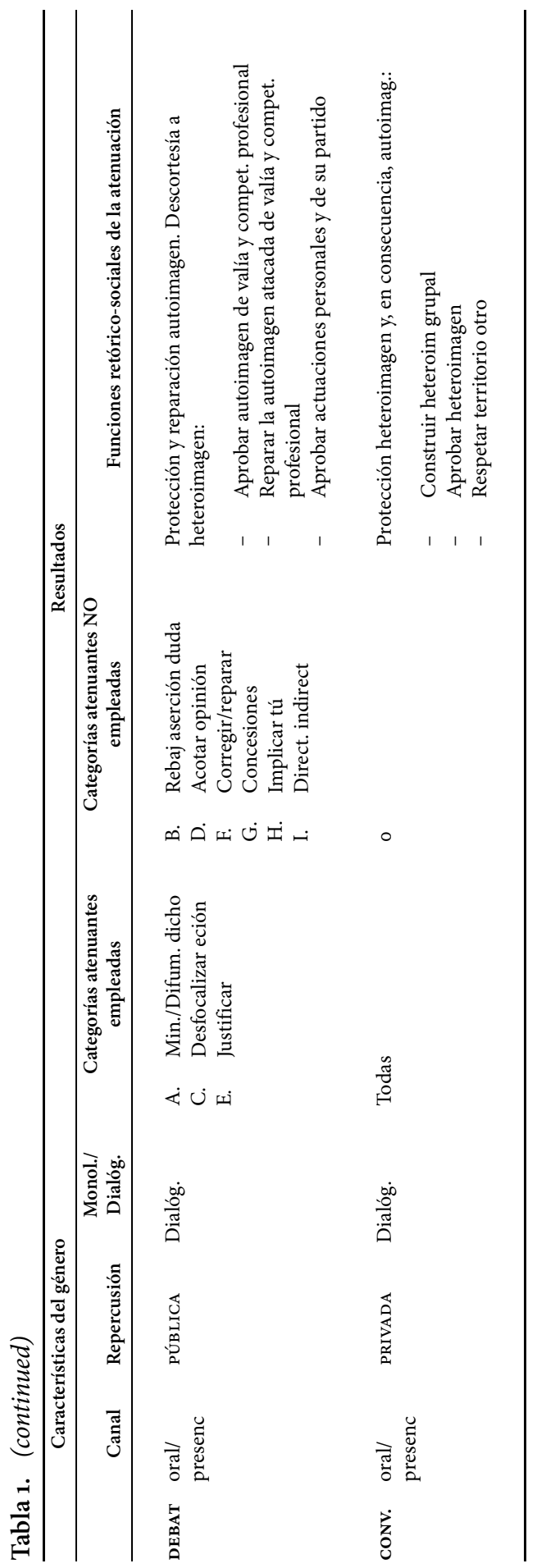


En los debates, aunque hay dialogicidad, apenas hay interacción. Cada candidato aprovecha la ocasión del debate para construir una autoimagen de profesional político competente; si surge interacción es para atacar a la heteroimagen. Ello explica que no se registre rebajamiento de la fuerza ilocutiva de aserción (B) ni acotación o restricción de las opiniones (B).

Las tres categorías atenuantes empleadas (A, C y E) en los debates están al servicio de la protección de la autoimagen, bien para protegerse del ataque del rival o de los presuntos juicios negativos de la audiencia hacia los políticos debatientes. En ese sentido, las justificaciones (J) son protectoras de la autoimagen y no de la heteroimagen, como también ocurre en los artículos; pero contrasta en las conversaciones y mesas redondas.

- Las respuestas en los foros TCA en internet dejan fuera los atenuantes de la categoría $\mathrm{B}$ y D, mitigadores de la opinión, puesto que esta función comunicativa apenas tiene relevancia. Lo que prima, por el contrario, es el consejo, y de ahí que sea el único género (además de la conversación) en que se registre la categoría I (directivos indirectos). También están al servicio de la suavización del consejo los atenuantes de tipo A, E, F, G y H. Las categorías F, G y H son propias de una protección de la heteroimagen, como también ocurre en las mesas redondas. La categoría $\mathrm{C}$ también cumple aquí el mismo papel, puesto que se desfocaliza especialmente a la segunda persona de la enunciación.

- Las necesidades de imagen destacadas en las mesas redondas combinan las actividades de imagen de los artículos académicos y de los foros TCA: protección de la autoimagen de experto y de la heteroimagen. De ahí que los atenuantes empleados en las mesas redondas sean la intersección de los utilizados en esos dos géneros.

\section{Conclusiones}

La Tabla 1 muestra de forma clara la diversidad de categorías atenuantes empleadas por género, así como la diversidad funcional en cuanto a las necesidades de imagen. Como se ha indicado al inicio del estudio, la variación de estrategias atenuantes en función del género y su correlación con particulares necesidades de imagen apunta a la fuerte implicación de la noción de imagen en la caracterización de la atenuación. El apartado anterior muestra cómo determinadas categorías atenuantes, como la corrección o las concesiones, se especializan en proteger las imágenes ajenas, o como, por ejemplo, la minimización y difuminación de lo dicho no son esperables para la expresión de una autoimagen de experto científico. 
En conclusión, los resultados del presente estudio revelan la incidencia del papel de la imagen en la definición de la atenuación. Junto con los criterios señalados por la bibliografía (lenguaje difuso, reducción de la fuerza ilocutiva, indireccionalidad de los actos de habla y/o desfocalización del papel de los hablantes de la enunciación), cabría añadir la protección de la imagen de los interlocutores, que en cada género se concretará de forma distinta.

Por último, este trabajo ha mostrado, una vez más, la necesidad de incorporar la perspectiva genérica a los estudios pragmáticos.

\section{Bibliografía}

Albelda, Marta. 2016. "Sobre la incidencia de la imagen en la atenuación pragmática”. RILI 27: 19-32.

Albelda, Marta. 2018. “'Atenuación del compromiso del hablante?: el caso de los evidenciales por lo visto y se ve que". Rilce 34(3).

Albelda, Marta y Ana Cestero. 2011. "De nuevo, sobre los procedimientos de atenuación”. Español actual 96: 121-155.

Albelda, Marta, Antonio Briz, Ana María Cestero, Dorota Kotwica y Cristina Villalba. 2014. "Ficha metodológica para el análisis pragmático de la atenuación en corpus lingüísticos del español". Oralia 17: 7-62.

Barros, Pedro (ed.). 2012. COGILA. Español oral conversacional: corpus y guía didáctica. Granada: Universidad.

Barros García, María Jesús. 2017. "Funciones de la atenuación en la conversación coloquial entre jóvenes del sur de España”. LEA 39 (2): 199-216.

Bazzanella, Carla, Claudia Caffi y Marina Sbisà. 1991. "Scalar dimension of illocutionary force. En Speech acts: fiction or reality? ed. por Igor Zagar, 63-76. Liubliana: IPrA.

Bravo, Diana. 1999. “¿Imagen positiva vs. imagen negativa? Pragmática social y componentes del face”. Oralia 2: 155-184.

Bravo, Diana. 2002. “Actos asertivos y cortesía: Imagen del rol en el discurso de académicos argentinos". En Actos de habla y cortesía en el español ed. por Diana Bravo y Elena Placencia, 141-174. Munich: Lincom Europa.

Briz, Antonio. 1995. "La atenuación en la conversación coloquial. Una categoría pragmática”. En El español coloquial. Actas del I Simposio sobre análisis del discurso oral ed. por Luis Cortés, 103-122. Almería: Servicio de Publicaciones, 103-122.

Briz, Antonio. 2006. "Para un análisis semántico, pragmático y sociopragmático de la cortesía atenuadora en España y América”. LEA: 1-38.

Briz, Antonio. 2012. "La (no)atenuación y la (des)cortesía, lo lingüístico y lo social: ¿son pareja?". En Miradas multidisciplinares a los fenómenos de cortesía y descortesía en el mundo hispánico ed. por Julio Escamilla, 33-75. Barranquilla/Estocolmo: Universidad del Atlántico.

Briz, Antonio y Marta Albelda. 2013. "Una propuesta teórica y metodológica para el análisis de la atenuación lingüística en español y portugués. La base de un proyecto común (ES.POR.ATENUACIÓN)". Onomazéin 28: 288-319. 
Cabedo, Adrián. 2016. "La función de la atenuación y la configuración prosódica: un estudio a partir de un corpus de español coloquial". RILI 27: 55-74.

Caffi, Claudia. 2007. Mitigation. Oxford: Elsevier.

Cestero, Ana María. 2015. "La atenuación lingüística en el habla de Madrid: un fenómeno sociopragmático variable". En Patrones sociolingüísticos de Madrid ed. por Ana María Cestero, Isabel Molina y Florentino Paredes, 365-412. Bern: Peter Lang.

Cestero, Ana María. 2017. "La atenuación en el habla de Madrid: patrones sociopragmáticos". Rilce 33 (1): 57-86.

Contreras, Josefa. 2012. “¿Hay diferencia en las estrategias de atenuación en los correos-electrónicos españoles y alemanes?”. Oralia 15: 325-242.

Czerwionka, Lori A. 2010. Mitigation in Spanish Discourse: Social and Cognitive Motivations, Linguistic Analyses, and Effects on Interaction and Interlocutors. Tesis doctoral. The University of Texas at Austin.

Douglas, Silvina, Amparo Soler y Joaquín Vuoto. 2018. "La atenuación en conversaciones coloquiales argentinas y españolas: un estudio contrastivo". Rilce 34(3).

Estellés, Maria. 2013. "La expresión fónica de la cortesía en tribunales académicos. Las intervenciones en tribunales de tesis y trabajos de investigación”. Oralia 16: 81-110.

Figueras, Carolina. 2016. "Atenuación y construcción de la identidad de experto en trastornos de la conducta alimentaria”. En Atenuación e intensificación en géneros discursivos ed. por Marta Albelda y Wiltrud Mihatsch, 169-186. Madrid/Frankfurt: Iberoamericana/ Vervuert.

Flores, María Eugenia. 2016. “Co-presencia de la atenuación e intensificación en el uso de bastante y su derivación en el habla del noreste de México". RILI 27: 137-152.

Fraser, Bruce. 1980. "Conversational mitigation". Journal of Pragmatics 4: 341-350. https://doi.org/10.1016/0378-2166(80)90029-6

Fuentes, Catalina. 2016. "Los marcadores de límite escalar: argumentación y "vaguedad" enunciativa”. Rilce 32 (1): 106-133.

González, Virgnia y Amparo García. 2017. “Atenuación e intensificación: estrategias pragmáticas del rechazo en respuestas a invitaciones en redes sociales en línea”. En Estrategias pragmáticas de intensificación y atenuación en géneros discursivos ed. por Marta Albelda y Wiltrud Mihatsch, 187-204. Madrid/Frankfurt: Iberoamericana/ Vervuert.

Hernández-Flores, Nieves. 2013. “Actividad de imagen. Caracterización y tipología en la interacción comunicativa”. Pragmática Sociocultural 1 (2): 1-24.

Hernández-Flores, Nieves y Vanessa Rodríguez (este volumen). "Lo que se debe hacer es cambiar un poco el estilo de vida': estrategias de atenuación en el consejo médico".

Holmes, Janet. 1984. "Modifying illocutionary forcé". Journal of Pragmatics 8: 345-365. https://doi.org/10.1016/0378-2166(84)90028-6

Hyland, Ken. 1998. Hedging in Scientific Research Articles. Amsterdam: John Benjamins. https://doi.org/10.1075/pbns.54

Lakoff, George. 1973. "Hedges: A Study in Meaning Criteria and the Logic of Fuzzy Concepts". Journal of Philosophical Logic 2: 458-507. https://doi.org/10.1007/BFoo262952

Markkanen, Raija y Hartmut Schröder (eds.). 1997. Hedging and Discourse. Approaches to the Analysis of a Pragmatic Phenomenon in Academic Texts. Berlín: Walter de Gruyter.

Meyer-Hermann, Reinhard. 1988. “Atenuación e intensificación (análisis pragmático de sus formas y funciones en español hablado)”. Anuario de Estudios Filológicos XI: 275-290. 
Morales, Óscar. A. 2010. Los géneros escritos de la Odontología hispanoamericana. Estructura retórica y estrategias de atenuación en artículos de investigación, casos clínicos y artículos de investigación. Barcelona: UPF.

Oliver del Olmo, Silvia. 2005. Análisis contrastivo español/inglés de la atenuación retórica en el discurso médico. El artículo de investigación y el caso clínico. Barcelona: UPF.

Samper, Marta. 2017. "Análisis sociolingüístico de la atenuación en el español de Las Palmas de Gran Canaria”. En Atenuación e intensificación en géneros discursivos ed. por Marta Albelda y Wiltrud Mihatsch, 153-168. Madrid/Frankfurt: Iberoamericana/Vervuert.

Sbisá, Marina. 2001. "Illocutionary force and degrees of strength in language use". Journal of Pragmatics 33: 1791-1814. https://doi.org/10.1016/S0378-2166(00)00060-6

Schneider, Stefan. 2013. "Atenuación léxica y sintáctica". Oralia 16: 335-356.

Schneider, Stefan. 2017. "Las dimensiones de la intensificación y la atenuación. En Atenuación e intensificación en géneros discursivos ed. por Marta Albelda y Wiltrud Mihatsch, 23-43. Madrid/Frankfurt: Iberoamericana/Vervuert.

Soler, María Amparo. 2018. "Fingimientos y atenuación en el uso de creo". Rilce 34 (3).

Thaler, Verena. 2012. "Mitigation as modification of illocutionary force". Journal of Pragmatics 44: 907-919. https://doi.org/10.1016/j.pragma.2012.04.001

Villalba, Cristina. 2016. Actividades de imagen, atenuación e impersonalidad en los juicios orales. Tesis Doctoral. Universitat de València.

\title{
Address for correspondence
}

\author{
Marta Albelda Marco \\ Universitat de València \\ Facultat de Filologia, Traducció i Comunicació \\ Av. Blasco Ibáñez 32. Valencia 46010 \\ València \\ España \\ marta.albelda@uv.es
}

Author Queries

- Please provide a complete reference for the citation '(Barros et al. 2012), (Cestero 2016), (Llopis 2016), (Flores-Treviño (2016)), (González y García (2016)), (Cestero y Albelda (2011)), (Lakoff (1972)), (Prince et al. 1982), (Briz et al. 2002), (Briz et al. 2012), (Tellería, J. L (2013)), (Cecchini-Estrada, J. A. et al. (2015)), (Lozano, C. et al. (2013))' in this article.

- Please provide a citation for the reference id "CITooo5 (Barros, Pedro (ed.). 2012), CIToo22 (Figueras, Carolina. 2016), CITo023 (Flores, María Eugenia. 2016), CITo026 (González, Virgnia y Amparo García. 2017), CITo031 (Lakoff, George. 1973)" since citation is missing in the article. 